\title{
Successful Treatment of latrogenic External Iliac Artery Perforation With Covered Stent: Case Report and Review of the Literature
}

\author{
Muhammad Umer Awan ${ }^{\mathrm{a}}$, Bassam Omar ${ }^{\mathrm{a}, \mathrm{b}}$, Ghazanfar Qureshi ${ }^{\mathrm{a}}$, \\ Ghulam Mustafa Awan ${ }^{a}$
}

\begin{abstract}
Retroperitoneal hemorrhage from iliac artery injury is a potentially serious complication of vascular interventional procedures leading to hemorrhagic shock and death if not diagnosed early and treated promptly. We report a 70-year-old male admitted to our facility with non-ST-elevation myocardial infarction, whose heart catheterization revealed left anterior descending artery (LAD) with $80 \%$ proximal, 95\% mid and 100\% distal disease. The left circumflex and right coronary arteries were $100 \%$ occluded proximally and received collaterals from the LAD. The patient declined coronary artery bypass surgery; therefore, the decision was made to perform high-risk percutaneous coronary intervention (PCI) of the LAD with Impella left ventricular assist device support. Left femoral artery angiogram revealed severely tortuous and calcified aorta, left external iliac and left common iliac arteries, and was accessed with 14-inch Impella sheath. He developed groin pain with mild hypotension thought to be due to sedation, which responded to intravenous fluids and dopamine. He underwent successful rotational atherectomy of the proximal and mid LAD with deployment of drug-eluting stents. Following PCI, he suffered acute profound hypotension necessitating intravenous fluids and vasopressor support with epinephrine. Emergency transthoracic echocardiogram did not reveal any pericardial effusion, and showed normal left ventricle and right ventricle systolic function. The Impella device was removed and selective left common iliac angiogram from the right femoral access revealed a vascular injury site with shift of the bladder to the right indicative of retroperitoneal hematoma. A digital subtraction angiogram revealed extravasation of blood at the vascular injury site. An $8.0 \times 59 \mathrm{~mm}$ iCAST covered stent was deployed to the left external iliac artery with successful sealing of the perforation. The Impella device site was closed with two Perclose devices. The patient required 4 units of packed red blood cell transfusion. His hospital course was complicated by transient acute kidney injury, with return of his renal function to baseline
\end{abstract}

Manuscript submitted August 19, 2017, accepted August 28, 2017

aDivision of Cardiology, University of South Alabama, Mobile, AL 36617, USA

${ }^{\mathrm{b} C}$ Corresponding Author: Bassam Omar, Division of Cardiology, University of South Alabama, Mobile, AL 36617, USA.

Email: omarbassamanwar@gmail.com

doi: https://doi.org/10.14740/cr596w at discharge 10 days later. This case underscores the importance of prompt recognition and treatment of vascular complications associated with interventional procedures, and highlights some of the risk predictors of such complications, which should be anticipated and planned for prior to intervention.

Keywords: Vascular perforation; Covered stent; Impella device

\section{Introduction}

Retroperitoneal hemorrhage from iliac artery injury is a potentially serious complication of vascular interventional procedures leading to hemorrhagic shock and death if not diagnosed early [1] and treated promptly. The reported incidence of retroperitoneal hematoma is $0.49-0.74 \%$ in patients after an interventional procedure and carries a mortality risk of $4-12 \%$ $[2,3]$. The use of covered stents to repair such vascular injuries has gained popularity given the high morbidity of emergency surgical vascular repair $[4,5]$. We report a life-threatening retroperitoneal bleed caused by an iatrogenic perforation of the left external iliac artery during Impella left ventricular assist device insertion for support in a high-risk coronary artery intervention procedure. The perforation was successfully sealed using an iCAST covered stent.

\section{Case Report}

A 70-year-old male with known coronary artery disease and stable angina was admitted to our facility with a prolonged chest pain episode at rest, associated with dyspnea. His electrocardiogram revealed diffuse ST and T wave abnormalities indicative of ischemia and his plasma troponin I levels increased from 0.07 to $0.23 \mathrm{ng} / \mathrm{mL}$. He was treated for nonST-elevation myocardial infarction and underwent left heart catheterization. This revealed left anterior descending artery (LAD) with $80 \%$ proximal, $95 \%$ mid and $100 \%$ distal disease (Fig. 1a). The left circumflex and right coronary arteries were $100 \%$ occluded proximally and received collaterals from the LAD. The patient declined coronary artery bypass surgery; therefore, the decision was made to proceed with high-risk 


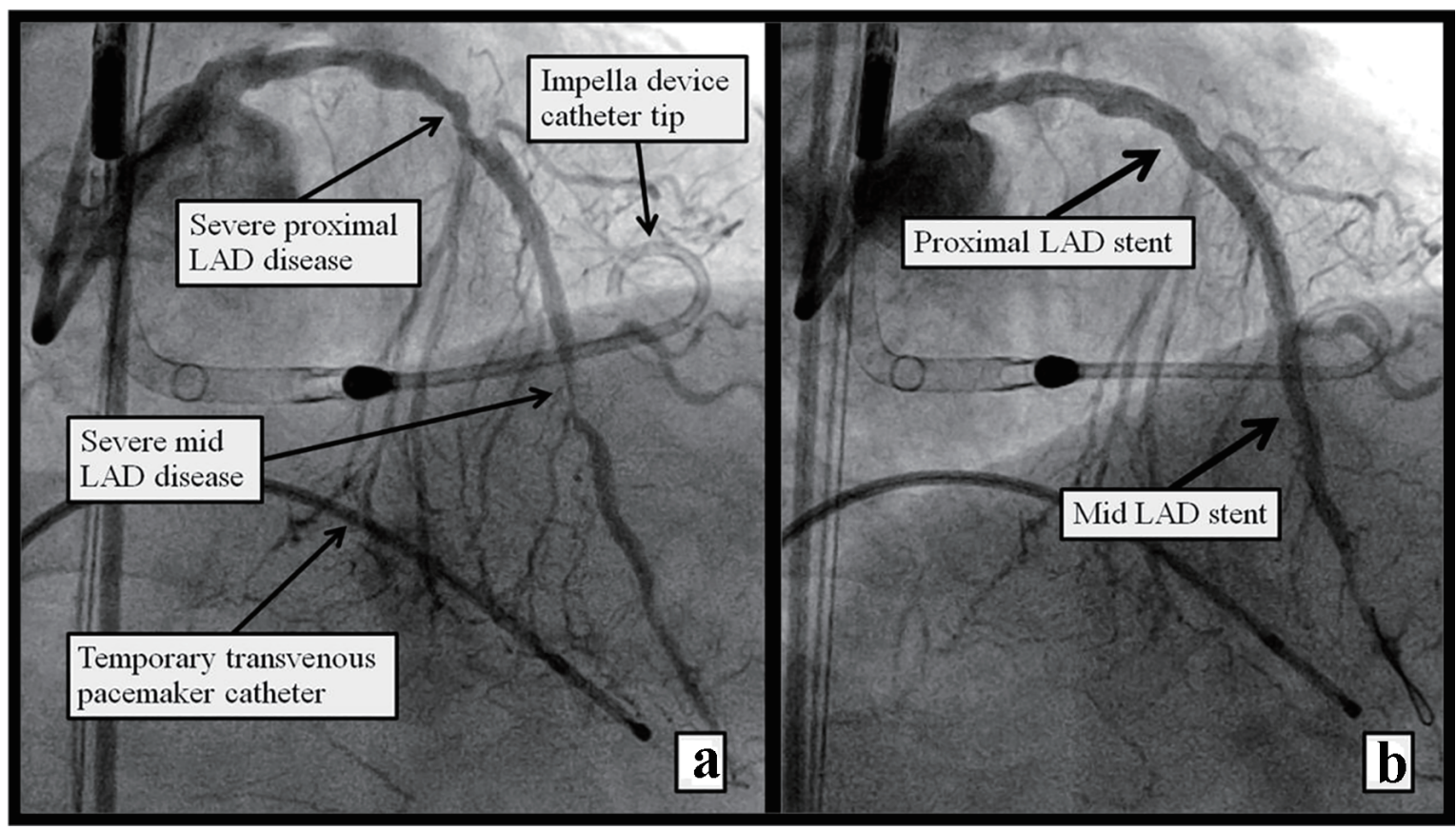

Figure 1. Figure 1. Left heart cathetrization RAO view showing (a) severe proximal and mid LAD disease pre PCI, Impella support device is seen in the LV, and a temporary transvenous pacemaker wire in the RV. (b) Post atherectomy and stent placement in the proximal and mid LAD.

percutaneous coronary intervention (PCI) of the LAD with Impella left ventricular assist device and temporary venous pacemaker support. Left femoral artery angiogram, accessed through a $45 \mathrm{~mm}$ Arrow sheath, revealed severely tortuous and calcified aorta, left external iliac and left common iliac artery. The left femoral access was pre-dilated and a 14-inch Impella sheath was introduced through the left common femoral artery. He developed groin pain at the access site with mild

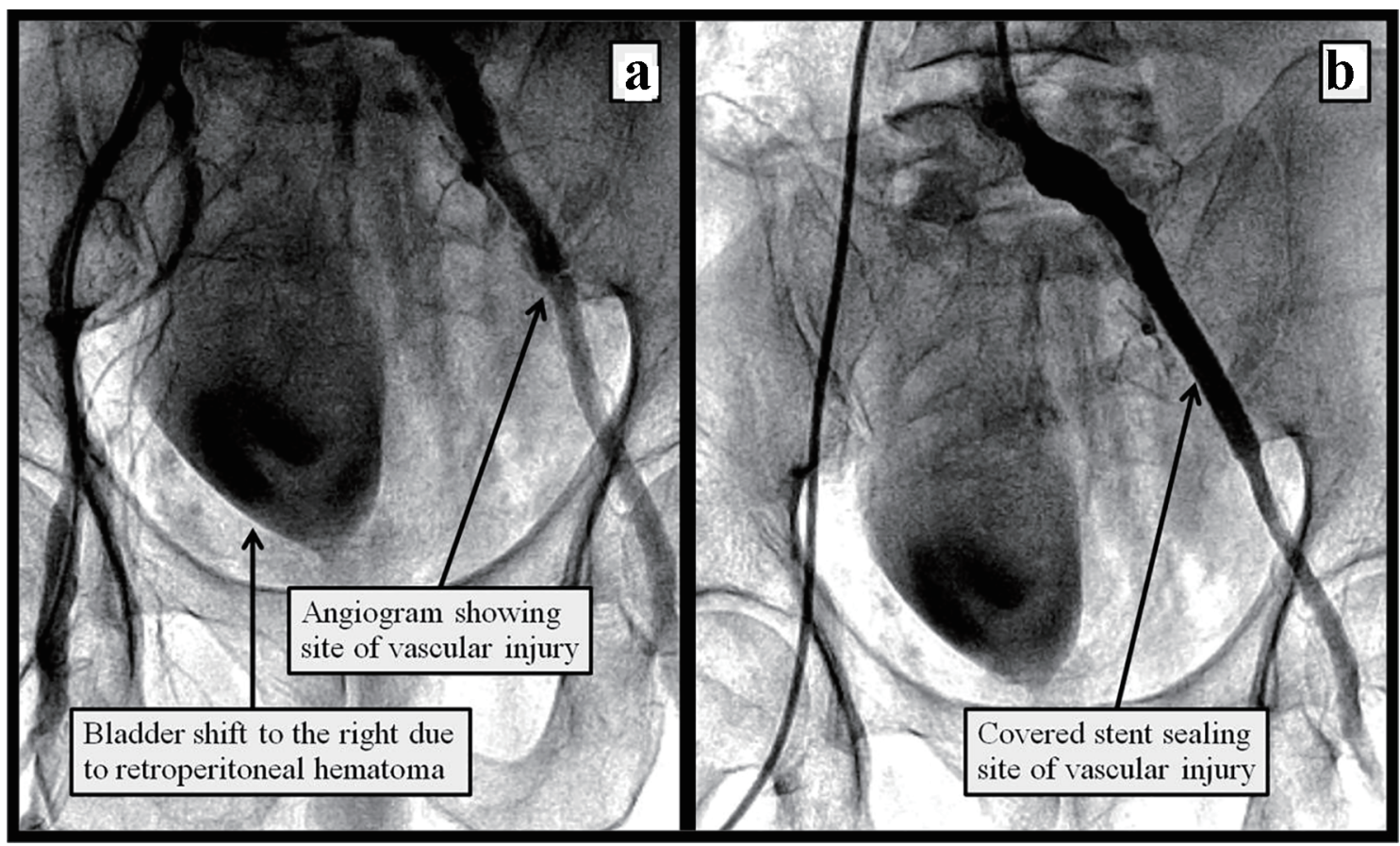

Figure 2. Figure 2. Peripheral angiogram of the left iliac artery showing (a) site of vascular injury and shift of the bladder to the right indicative of compression from the rapidly accumulating retroperitoneal hemaoma; (b) after endovascular repair of the left iliac perforation using a covered stent. 


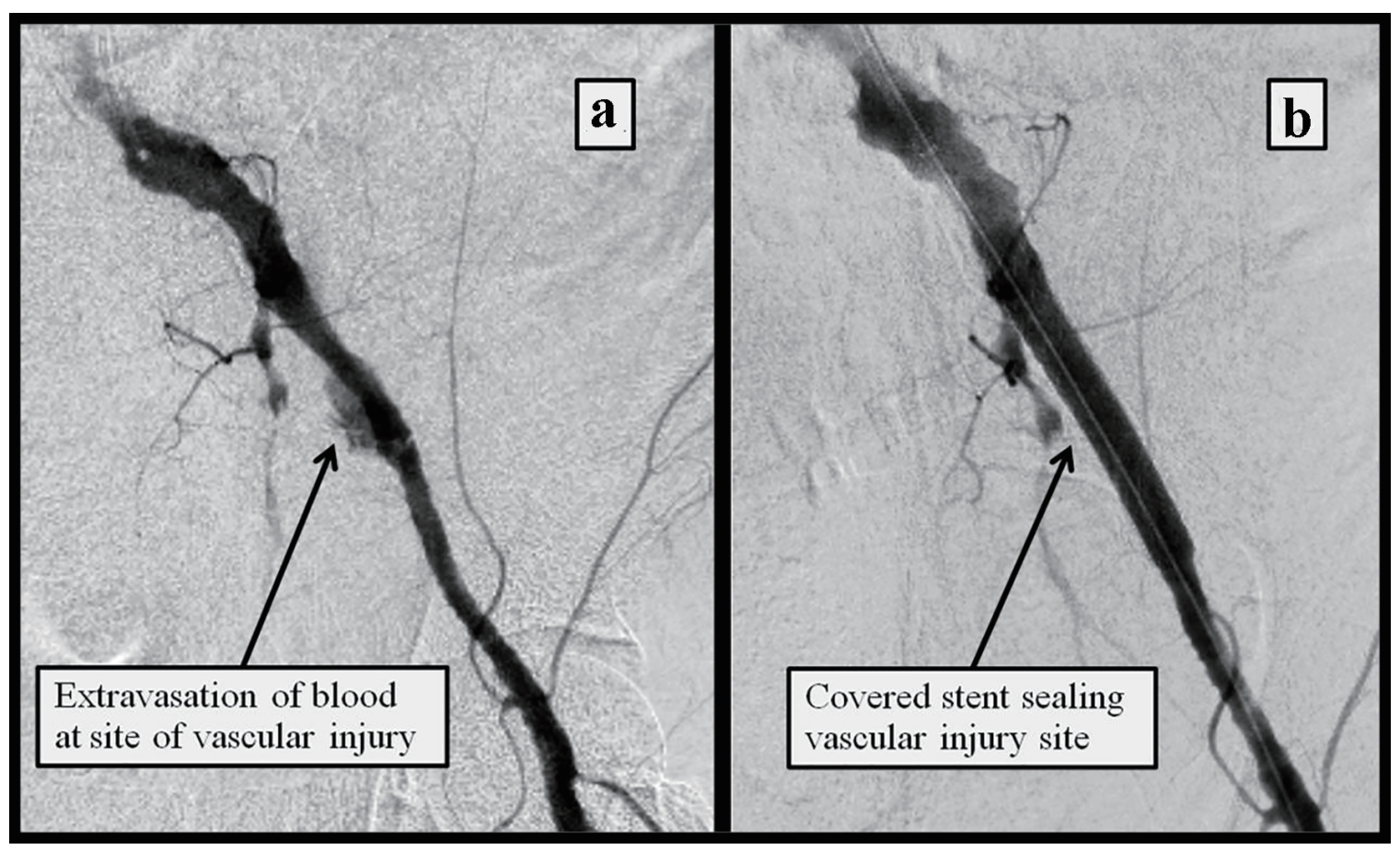

Figure 3. DSA of the left iliac artery showing (a) extravasation of blood into the retroperitoneal space at the site of vascular perforation; (b) resolution of the bleeding following the deployment of a covered stent.

hypotension thought to be due to sedation given, including versed and fentanyl, which responded to intravenous fluids and dopamine. He underwent successful rotational atherectomy of the proximal and mid LAD with deployment of Synergy (Boston Scientific) drug-eluting stents (Fig. 1b). Following PCI, the patient suffered acute profound hypotension necessitating intravenous fluids and vasopressor support with epinephrine. Emergency transthoracic echocardiogram did not reveal any pericardial effusion, and showed normal left ventricle (LV) and right ventricle (RV) systolic function. The Impella device was removed and selective left common iliac angiogram from the right femoral access revealed a vascular injury site with shift of the bladder to the right indicative of retroperitoneal hematoma (Fig. 2a). A digital subtraction angiogram (DSA) revealed extravasation of blood at the vascular injury site (Fig. 3a). An $8.0 \times 59 \mathrm{~mm}$ iCAST covered stent was deployed to the left external iliac artery with successful sealing of the perforation (Figs. $2 b$ and $3 b$ ). The Impella device site was closed with two Perclose devices. Computed tomography (CT) of the abdomen revealed large retroperitoneal bleeding along the plane of left external iliac artery (Fig. 4a, b). The patient required 4 units of packed red blood cell transfusion. His hospital course was complicated by transient acute kidney injury, with return of his renal function to baseline at discharge 10 days later.

\section{Discussion}

With the advent of progressively sophisticated endovascular therapies to treat vascular, coronary, valvular and other struc- tural heart disease, the use of increasingly larger sheaths has been associated with a surge in iatrogenic vascular access complications [6]. Vascular perforation or rupture is a serious potential complication of any endovascular procedures and can lead to organ, limb, or life loss. The management of this deleterious complication has evolved from emergent surgery [7] to now include multiple percutaneous options including the use of prolonged balloon tamponade [8], stent grafts [9], coil embolization [10], vascular plug [11], coagulated thrombus injection [12] and localized thrombin injection [13]. Iatrogenic iliac artery injuries including dissection and perforation appear to be more common in patients with calcified atherosclerotic aorto-iliac disease and tortuous vessels [14], as was seen in our patient.

Case series or trials studying the use of devices to treat iliac artery perforation or rupture are few. One series [15] analyzed 1,642 peripheral interventions (46\% iliac and 54\% femoro-distal) and reported only two cases of perforation and hematoma requiring surgery (one retroperitoneal hemorrhage and one pseudo-aneurysm). Palmaz et al [16] reported a $0.9 \%$ incidence (five out of 587 procedures) of vessel rupture and pseudo-aneurysms in patients who underwent iliac artery stenting procedures. Allaire et al [17] examined 657 iliac interventions from 1981 to 2000 and found a $0.8 \%$ incidence (five patients) of vessel rupture; they recommended covered stents to treat ruptured vessels.

Risk factors associated with rupture [17-19] include calcified vessels, vascular stenosis, oversized balloons, history of recent endarterectomy, chronic steroid therapy, and diabetes mellitus. Some authors have used balloon tamponade for a few minutes as a treatment for contained bleeding [8, 19], but this 


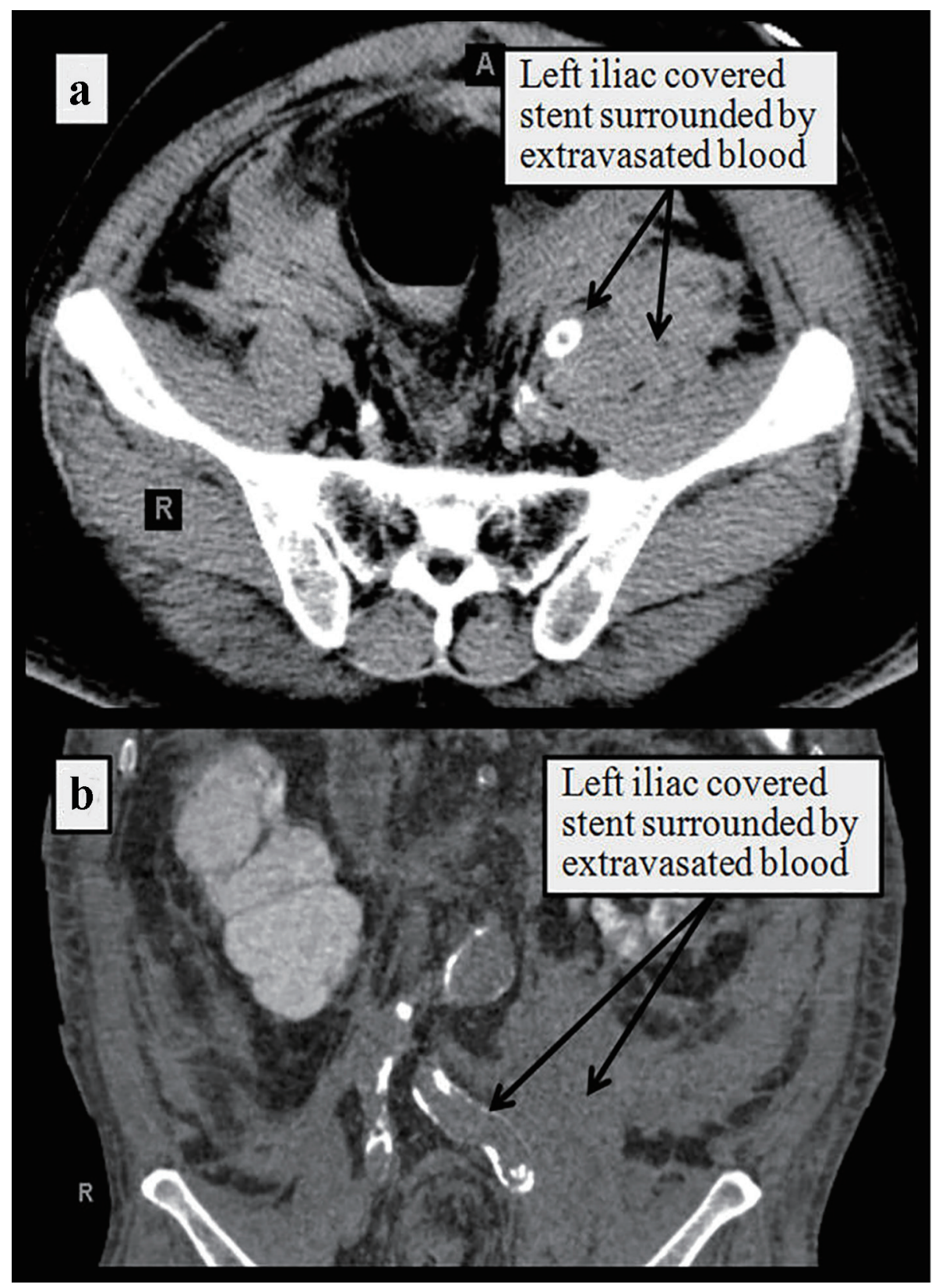

Figure 4. CT of the abdomen without contrast in transverse (a) and coronal (b) planes showing site of the covered stent surrounded by retroperitoneal hemorrhage along the plane of left external iliac artery.

method is thought to be unreliable as bleeding may resume later. In a recent series of seven iliac artery ruptures [20], all were successfully treated with stent grafts.

Endovascular therapy of traumatic and iatrogenic vascular complications varies among reports in the literature. Lagana et al [21] reported 13 patients with traumatic and iatrogenic arterial iliac ruptures who were all treated successfully with stent grafts. Hamilos and colleagues [22] reported successfully treating a large iliac artery rupture with a coated stent. Trehan et al [23] used a longer stent-graft on a shorter balloon to emergently treat an iatrogenic iliac artery rupture. Mehta et al [24] successfully treated a massive bleed from a guidewire perforation of an external iliac artery with hand-made stentgraft placement. Arat and colleagues [25] reported successful treatment of a femoral bleeding site with two covered selfexpanding coronary stent-grafts. Nozary and Hashemi Fard [26] reported a rare simultaneous dissection, perforation and thrombosis of the external iliac artery following angiography which did not respond to firm compression and required arteriotomy and vascular repair. Overall, iliac artery injury and rupture outcomes have significantly improved, especially as endoluminal management has evolved as the primary treatment strategy [27].

With the introduction of the radial approach to endovas- 
Table 1. Predictors of latrogenic Vascular Complications Reported in the Literature, Divided in Potentially Modifiable Versus Non-Modifiable Factors

\begin{tabular}{ll}
\hline Potentially modifiable & Non-modifiabe \\
\hline High femoral artery puncture & Diffuse vascular calcifications \\
\hline Larger sheath size & Increased vascular tortuousity \\
Excessive guidewire manipulation & High grade iliac stenosis \\
Manual inflation (pressure and time) & Female gender \\
Oversized balloon & Older age \\
Procedure time & Low body surface area (BSA) \\
Anticoagulation or thrombolytics & Chronic kidney disease (CKD) \\
Hypertension during procedure & Diabetes mellitus (DM) \\
Patient agitation and movement & Prior stroke \\
Long-term steroid therapy & Connective tissue disease (e.g. Ehlers Danlos) \\
\hline
\end{tabular}

cular procedures, vascular complications of the radial artery have been increasingly reported. Chatterjee et al [28], Narayan et al [29] and Al-Sekaiti et al [30] all reported successfully treating radial artery perforation during transradial catheterization using polytetrafluoroethylene-covered coronary stents. Other vascular injuries have also been reported with successful endovascular repair using covered stents including carotid injury [31, 32], subclavian injury [33], brachial injury [34] and traumatic vascular injuries [35].

Iatrogenic iliac artery injury during other intravascular or orthopedic surgery has been reported, with successful endovascular repair. Wozniak et al [36] reported six out of 328 patients $(1.8 \%)$ undergoing endovascular surgery for iliac stenosis sustained iliac injury, four of whom received endovascular treatment while two required classical vascular surgery. Adovasio et al [37] and Kwolek et al [38] reported endovascular treatment of iliac artery injury following hip arthroplasty and hip prosthesis migration, respectively. Canaud et al [39] reported successful endovascular repair of iliac artery injury following lumbar spine surgery. Barbosa Barros et al [40] reported five cases of iliac artery injuries secondary to laparoscopic gynecologic procedures over a 10 -year period, all treated surgically. Wang and Foley [41], however, reported successful endovascular repair of an iliac artery aneurysm and ilio-iliac fistula,

Table 2. Procedures Reported in the Literature to Treat latrogenic Vascular Complications

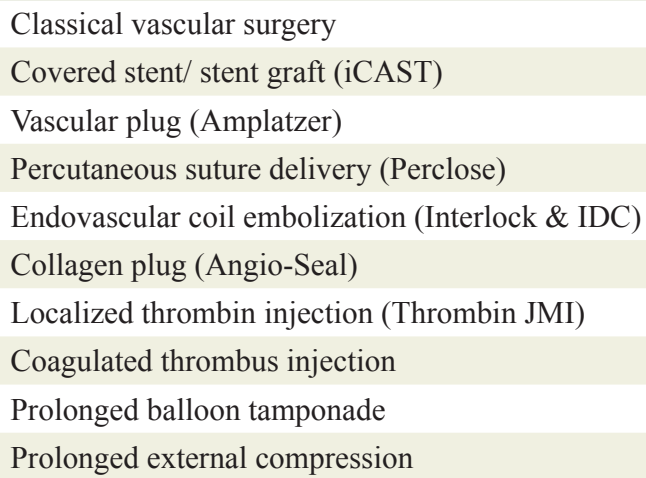

sustained during laparoscopic hysterectomy.

\section{Conclusion}

Iatrogenic or traumatic vascular injuries remain uncommon, however, with a rising incidence due to the increasing number of endovascular therapies requiring larger catheters and sheaths and offered to older individual with vulnerable vascular anatomy. Table 1 lists some of the reported predictors for iatrogenic vascular injury which should be taken into consideration during any intravascular procedure. Although multiple modalities have been employed to seal vascular ruptures depending on the extent of bleeding and size of perforation (Table 2), endovascular treatment with covered stents appears to have emerged as the treatment of choice, especially for large, life-threatening perforations [42, 43], with great success rates of immediate control of bleeding, in addition to adequate patency rates on follow-up. When planning a coronary revascularization strategy, we recommend that a multidisciplinary team approach be implemented not only with a Heart Team approach to decide about the best interventional modality, but also with a vascular interdisciplinary team approach to help mitigate the potential risk of iatrogenic vascular complications (Fig. 5).

\section{Disclosures}

All authors declare no disclosures related to this manuscript.

\section{References}

1. Hingorani AP, Ascher E, Marks N, Shiferson A, Patel N, Gopal K, Jacob T. Iatrogenic injuries of the common femoral artery (CFA) and external iliac artery (EIA) during endograft placement: an underdiagnosed entity. J Vasc Surg. 2009;50(3):505-509; discussion 509.

2. Tiroch KA, Arora N, Matheny ME, Liu C, Lee TC, 

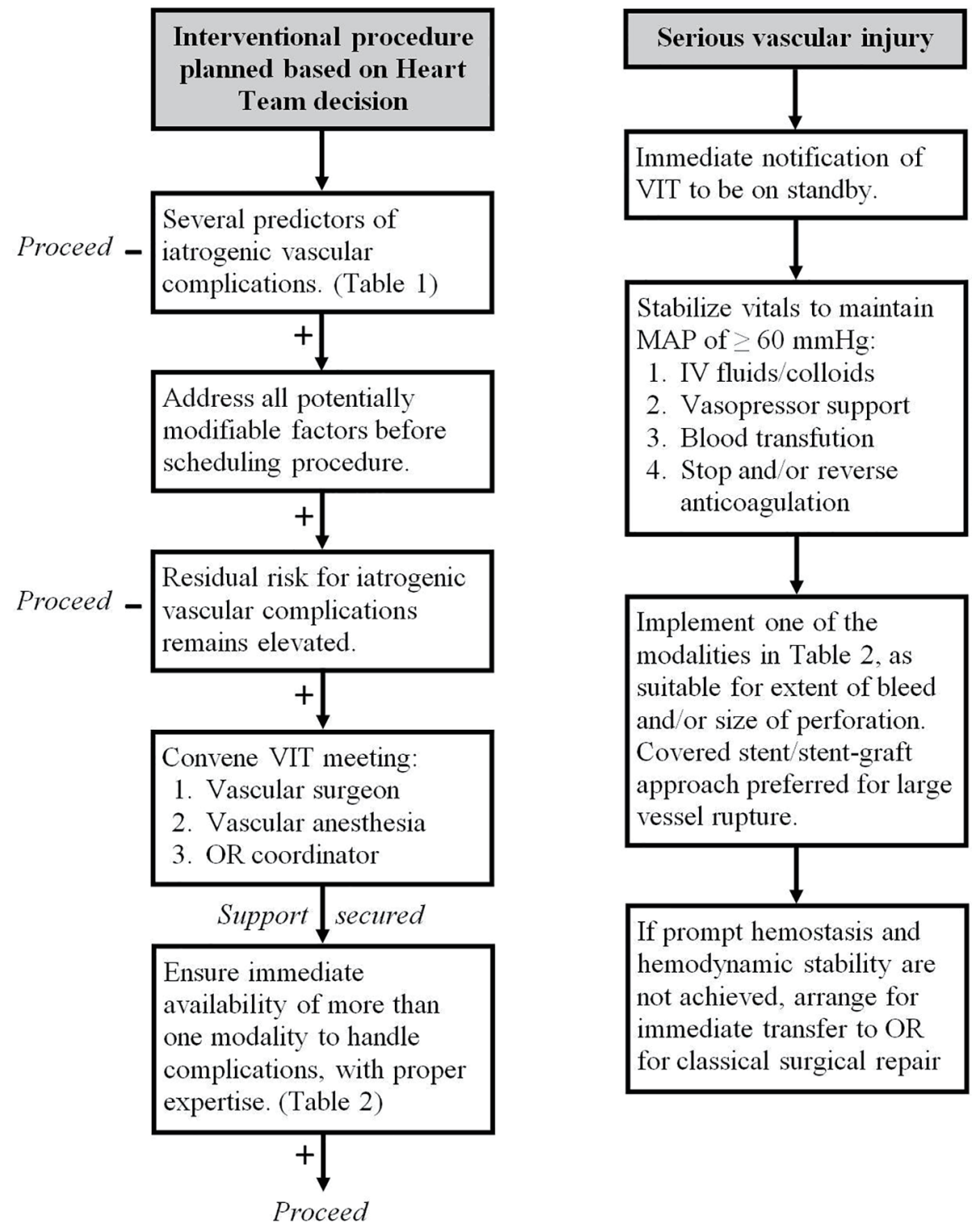

Figure 5. Vascular interdisciplinary team (VIT) approach to help mitigate the risk of iatrogenic vascular complications during planned interventional procedures. OR: operating room; MAP: mean arterial pressure.

Resnic FS. Risk predictors of retroperitoneal hemorrhage following percutaneous coronary intervention. Am J Cardiol. 2008;102(11):1473-1476.

3. Farouque HM, Tremmel JA, Raissi Shabari F, Aggarwal M, Fearon WF, Ng MK, Rezaee M, et al. Risk factors for the development of retroperitoneal hematoma after percutaneous coronary intervention in the era of glycoprotein IIb/IIIa inhibitors and vascular closure devices. J Am Coll Cardiol. 2005;45(3):363-368.

4. Nyman U, Uher P, Lindh M, Lindblad B, Brunkwall J, Ivancev K. Stent-graft treatment of iatrogenic iliac artery perforations: report of three cases. Eur J Vasc Endovasc Surg. 1999; 17(3):259-263.

5. Kufner S, Cassese S, Groha P, Byrne RA, Schunkert H, Kastrati A, Ott I, et al. Covered stents for endovascular repair of iatrogenic injuries of iliac and femoral arteries. Cardiovasc Revasc Med. 2015;16(3):156-162.

6. Lejay A, Caspar T, Ohana M, Delay C, Girsowicz E, Ohlmann $\mathrm{P}$, Thaveau $\mathrm{F}$, et al. Vascular access complications in endovascular procedures with large sheaths. J Cardiovasc Surg (Torino). 2016;57(2):311-321.

7. May J, White GH, Yu W, Waugh RC, Stephen MS, McGahan T, Harris JP. Surgical management of complications following endoluminal grafting of abdominal aortic aneurysms. Eur J Vasc Endovasc Surg. 1995;10(1):51-59.

8. Cooper SG, Sofocleous CT. Percutaneous management of angioplasty-related iliac artery rupture with preservation of luminal patency by prolonged balloon tamponade. J Vasc Interv Radiol. 1998;9(1 Pt 1):81-83.

9. Jamshidi P, Mahmoody K, Erne P. Covered stents: a re- 
view. Int J Cardiol. 2008;130(3):310-318.

10. Kruger K, Siakavara E. Coil embolization for treatment of vascular complications after nephron-sparing surgery. Acta Radiol. 2012;53(5):551-555.

11. Ryer EJ, Garvin RP, Webb TP, Franklin DP, Elmore JR. Comparison of outcomes with coils versus vascular plug embolization of the internal iliac artery for endovascular aortoiliac aneurysm repair. J Vasc Surg. 2012;56(5):12391245.

12. Tokuda T, Hirano K, Yamawaki M, Araki M, Kobayashi N, Mori S, Sakamoto Y, et al. Efficacy and safety of a coagulated thrombus injection for peripheral artery perforation: The coagulated thrombus hemostasis method. Catheter Cardiovasc Interv. 2017.

13. Mohler ER, 3rd, Mitchell ME, Carpenter JP, Strandness DE, Jr., Jaff MR, Beckman JA, Gerhard-Herman M. Therapeutic thrombin injection of pseudoaneurysms: a multicenter experience. Vasc Med. 2001;6(4):241-244.

14. Vavuranakis M, Kariori M, Voudris V, Kalogeras K, Vrachatis D, Aznaouridis C, Moldovan C, et al. Predictive factors of vascular complications after transcatheter aortic valve implantation in patients treated with a default percutaneous strategy. Cardiovasc Ther. 2013;31(5):e4654.

15. Belli AM, Cumberland DC, Knox AM, Procter AE, Welsh $\mathrm{CL}$. The complication rate of percutaneous peripheral balloon angioplasty. Clin Radiol. 1990;41(6):380-383.

16. Palmaz JC, Laborde JC, Rivera FJ, Encarnacion CE, Lutz JD, Moss JG. Stenting of the iliac arteries with the Palmaz stent: experience from a multicenter trial. Cardiovasc Intervent Radiol. 1992;15(5):291-297.

17. Allaire E, Melliere D, Poussier B, Kobeiter H, Desgranges $\mathrm{P}$, Becquemin JP. Iliac artery rupture during balloon dilatation: what treatment? Ann Vasc Surg. 2003;17(3):306314.

18. Lois JF, Takiff H, Schechter MS, Gomes AS, Machleder HI. Vessel rupture by balloon catheters complicating chronic steroid therapy. AJR Am J Roentgenol. 1985;144(5):1073-1074.

19. Smith DC, Hirst AE. Spontaneous aortic rupture associated with chronic steroid therapy for rheumatoid arthritis in two cases. AJR Am J Roentgenol. 1979;132(2):271-273.

20. Chatziioannou A, Mourikis D, Katsimilis J, Skiadas V, Koutoulidis V, Katsenis K, Vlahos L. Acute iliac artery rupture: endovascular treatment. Cardiovasc Intervent Radiol. 2007;30(2):281-285.

21. Lagana D, Carrafiello G, Mangini M, Giorgianni A, Lumia D, Cuffari S, Fugazzola C. Emergency percutaneous treatment of arterial iliac axis ruptures. Emerg Radiol. 2007;14(3):173-179.

22. Hamilos MI, Kochiadakis GE, Hatzidakis AA, Vardas PE. Treatment of a large rupture of the external iliac artery by implantation of a coated metal stent. Hellenic J Cardiol. 2005;46(5):354-355.

23. Trehan V, Nigam A, Ramakrishnan S. Iatrogenic iliac artery rupture: emergency management by longer stentgraft on a shorter balloon. Cardiovasc Intervent Radiol. 2007;30(1):108-110.

24. Mehta V, Pandit BN, Mehra P, Nigam A, Vyas A, Yusuf
J, Mukhopadhyay S, et al. Massive Bleeding from Guidewire Perforation of an External Iliac Artery: Treatment with Hand-made Stent-Graft Placement. Cardiovasc Intervent Radiol. 2016;39(1):106-110.

25. Arat A, Turkbey B, Cil BE, Canyigit M, Cekirge S. Emergent treatment of an Iatrogenic arterial injury at femoral puncture site With Symbiot self-expanding PTFE-covered coronary stent-graft. Australas Radiol. 2007;51(Suppl):B331-333.

26. Nozary Y, Hashemi Fard O. Rare occurrence of simultaneous dissection, perforation and thrombosis of external iliac artery following diagnostic coronary angiography: a case report. ARYA Atheroscler. 2010;6(2):82-84.

27. Duran C, Naoum JJ, Smolock CJ, Bavare CS, Patel MS, Anaya-Ayala JE, Lumsden AB, et al. A longitudinal view of improved management strategies and outcomes after iatrogenic iliac artery rupture during endovascular aneurysm repair. Ann Vasc Surg. 2013;27(1):1-7.

28. Chatterjee A, White JS, Leesar MA. Management of radial artery perforation during transradial catheterization using a polytetrafluoroethylene-covered coronary stent. Cardiovasc Revasc Med. 2017;18(2):133-135.

29. Narayan RL, Vaishnava P, Kim M. Radial artery perforation during transradial catheterization managed with a coronary polytetrafluoroethylene-covered stent graft. J Invasive Cardiol. 2012;24(4):185-187.

30. Al-Sekaiti R, Ali M, Sallam M. Radial artery perforation after coronary intervention: is there a role for covered coronary stent? Catheter Cardiovasc Interv. 2011;78(4):632635.

31. Agid R, Simons M, Casaubon LK, Sniderman K. Salvage of the carotid artery with covered stent after perforation with dialysis sheath. A case report. Interv Neuroradiol. 2012;18(4):386-390.

32. Dieter RS, Ikram S, Satler LF, Babrowicz JC, Reddy B, Laird JR. Perforation complicating carotid artery stenting: the use of a covered stent. Catheter Cardiovasc Interv. 2006;67(6):972-975.

33. Melas N, Saratzis A, Saratzis N, Kiskinis D. Endovascular repair of inadvertent subclavian artery perforation during cannulation for dialysis access: case report and review of the literature. Eur J Emerg Med. 2009;16(6):323326.

34. Kelly D, Levy T, Talwar S. Brachial artery perforation repaired with percutaneous transfemoral covered stent deployment in a patient on abciximab. J Invasive Cardiol. 2008;20(3):E82-83.

35. White R, Krajcer Z, Johnson M, Williams D, Bacharach M, O'Malley E. Results of a multicenter trial for the treatment of traumatic vascular injury with a covered stent. J Trauma. 2006;60(6):1189-1195; discussion 1195-1186.

36. Wozniak W, Mlosek RK, Zydlewski P, Milek T, Myrcha P, Kowalski M, Ciostek P. Treatment of iatrogenic iliac artery rupture during endovascular surgery. Acta Angiol. 2011;17(2):150-157.

37. Adovasio R, Mucelli FP, Lubrano G, Gasparini C, Belgrano M, Griselli F, Fancellu G. Endovascular treatment of external iliac artery injuries after hip arthroplasty. J Endovasc Ther. 2003;10(3):672-675. 
38. Kwolek CJ, Matthews MR, Hartford JM, Minion DJ, Schwarcz TH, Quick R, Endean E. Endovascular repair of external iliac artery occlusion after hip prosthesis migration. J Endovasc Ther. 2003;10(3):668-671.

39. Canaud L, Hireche K, Joyeux F, D'Annoville T, Berthet JP, Marty-Ane C, Alric P. Endovascular repair of aortoiliac artery injuries after lumbar-spine surgery. Eur J Vasc Endovasc Surg. 2011;42(2):167-171.

40. Barbosa Barros M, Lozano FS, Queral L. Vascular injuries during gynecological laparoscopy - the vascular surgeon's advice. Sao Paulo Med J. 2005;123(1):38-41.
41. Wang GJ, Foley PJ. Endovascular Repair of Iatrogenic Iliac Injuries Successful endovascular exclusion of an iliac artery pseudoaneurysm and ilio-iliac arteriovenous fistula sustained during laparoscopic hysterectomy. Endovascular today. 2011:29-30.

42. Yeo KK, Rogers JH, Laird JR. Use of stent grafts and coils in vessel rupture and perforation. J Interv Cardiol. 2008;21(1):86-99.

43. Baltacioglu F, Cimsit NC, Cil B, Cekirge S, Ispir S. Endovascular stent-graft applications in latrogenic vascular injuries. Cardiovasc Intervent Radiol. 2003;26(5):434-439. 